\title{
Age and sex affect osteoarthritis and the outcome on knee replacement
}

\begin{abstract}
Background: Arthrosis has a huge impact due to its consequences on suffering and function loss and because it damages the well-being and the physical, emotional and social aspects of Health-Related Quality of Life. Our objective was to assess the influence of Age and Sex on Knee Osteoarthritis and Total Knee Arthroplasty on the perception of the patients with regard to their quality of life, before and after the intervention.
\end{abstract}

Method: We carried out a quasi-experimental intervention study with a before and after design in a sample of 125 patients with knee osteoarthritis who were assessed before and after the operation. They all were operated by the same orthopedic surgeon and with the same type of total knee arthroplasty between the year 2008 and 2012. The Health-Related Quality of Life was assessed with the questionnaire SF-36.

Results: We have observed that knee osteoarthritis significantly affects all the dimensions of Health-Related Quality of Life before the operation and that all the dimensions included in the SF-36 show a clinical improvement after the intervention with total knee arthroplasty. Female Sex has an influence diminishing Physical Function $(p=0.044)$ in Knee Osteoarthritis (before the intervention), but it does not influence the outcome after Total Knee arthroplasty. Age has an influence on Bodily Pain $(p=0.012)$ and Vitality $(p=0.002)$ in knee Osteoarthritis (before the intervention), and on Physical $(\mathrm{p}=0.040)$ and Mental Health Components $(p=0.002)$ after Total Knee arthroplasty. However, we can state that the operation of total knee arthroplasty significantly improves Health-Related Quality of Life in all its dimensions and components, except for Physical Functioning and Role-Physical, although they also improve over time after the operation.

Conclusion: Total knee arthroplasty is justified according to the perception of clinical improvement and the improvement of Health-Related Quality of Life reported by the patients. Sex influences Knee Osteoarthritis and Age influences on Knee OA and Total Knee Arthroplasty outcomes.

Keywords: Knee Osteoarthritis, Quasi-experimental intervention study, Total Knee Arthroplasty, Health-Related Quality of Life, Risk Factors, Age, Sex
Volume 9 Issue 4 - 2017

\author{
Marcos E Fernández-Cuadros, ${ }^{1,2}$ Olga S \\ Pérez-Moro, ${ }^{2}$ Monserrat Alonso-Sardón, ${ }^{3}$

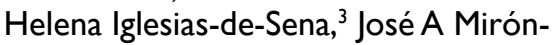 \\ Canelo ${ }^{3}$ \\ 'Department of Rehabilitation and Physical Medicine, Sant \\ 2Department of Rehabilitation and Physical Medicine, Santa \\ Cristina's University, Spain \\ ${ }^{3}$ Department of Preventive Medicine and Public Health, \\ University of Salamanca, Spain
}

Correspondence: Marcos Edgar Fernandez-Cuadros, Calle del Ansar, 44, piso segundo, 28047. Madrid, Spain, Tel 34 6203I4558 Emailmacosefc@hotmail.com

Received: October 17, 2017 | Published: November 21, 2017

\section{Abbreviations}

OA, Osteoarthritis; HRQOL, Health-Related Quality of Life; TKA, Total Knee Arthroplasty

\section{Introduction}

Osteoarthritis is a degenerative, disabling and multifactorial disease with a high prevalence that increases exponentially with age. ${ }^{1-}$ ${ }^{3}$ It is divided into categories as primary and secondary Ostearthritis, depending on the related causes. ${ }^{2}$ It mainly affects weight bearing joints such as knees and hips, which are the most frequently affected areas. ${ }^{2}$ Knee osteoarthritis is more disabling than any other orthopedic and musculoskeletal disorder. ${ }^{2}$

The impact of osteoarthritis is huge regarding suffering, function loss and use of social-health resources. Also, it worsens wellbeing and Health-Related Quality of Life (HRQOL) in its physical, emotional and social aspects. ${ }^{2}$ Consequently, it is important to know the impact of this condition on HRQOL in order to make therapeutic decisions in the context of health policies related to the efficiency and sustainability of the health system. ${ }^{4}$

Health-Related Quality of Life is expressed as the degree of perception to which the disease or its treatment affects the physical, psychic, emotional and social abilities of an individual. ${ }^{5}$ It is a global index of clinical results in the field of Health which makes it possible to associate the therapeutic/surgical objectives with the results obtained in the individual and social spheres of the patient. Also, it can be measured with generic or specific health questionnaires. ${ }^{6}$

Total knee arthroplasty (TKA) is the orthoprosthetic operation with the highest clinical success rate, with good prognosis and sustained clinical results in over $95 \%$ of the patients after 10 years. Also, it reduces pain and improves function and HRQOL.?

There is controversy on whether age and sex are risk factors that could influence on Knee Osteoarthritis and Total Knee Arthroplasty. However, there is agreement that $\mathrm{OA}$ is more frequent in older people and in females. ${ }^{1-5}$

The objective of this study is to assess the influence of the clinical intervention (TKA) from the perspective of the perception of the operated patient with regard to HRQOL. Also, we want to analyze Age and Sex can affect these results. The hypothesis of this work is based on the fact that there are no statistically significant clinical differences between Age/Sex and HRQOL of patients with knee osteoarthritis before and after the operation.

\section{Methods}

In order to reach our objectives and prove our hypothesis, a quasiexperimental intervention study with a before and after design was 
carried out. It is an experimental or intervention study on a sample of patients with knee osteoarthritis who were assessed before and after the operation of TKA. This type of epidemiological study has a good scientific evidence level, according to the categories and classification proposed by the Task Force US and the Centre for Evidence Based Medicine (CEBM) of Oxford. ${ }^{8,9}$

The clinical research was carried out in the Health Area of Salamanca, which comprises the Clinical University Hospital of Salamanca, and it included all patients with severe knee osteoarthritis who were referred by Primary Care Doctors in order to assess the possibility of a surgical operation.

Our series was made up of 125 (46.8\%) patients out of a total of 267 patients. They were all operated by the same orthopedic surgeon and with the same type of TKA (Scorpio-Stryker ${ }^{\circledR}$ ) between the years 2008 and 2012. All the patients filled out the SF-36 survey before and after the operation, and their clinical history was reviewed in order to obtain the independent variables related with HRQOL, such as age, sex, comorbidities, other arthroplasties, other operations on the locomotor system, and in-hospital stay.

The criteria for inclusion as CASES were: adult patients of any age and sex with a diagnosis of osteoarthritis of the knee who were operated with TKA type Scorpio and/or with diverse comorbidities. The criteria for exclusion were: patients with disorders and/or pathologies that prevented them from knowing, understanding or assessing their clinical situation. Also those in which it was impossible to obtain updated personal data or who failed to attend the post-intervention interview in which the questionnaire was filled out, after the first post-intervention visit, which took place after 2 to 3 months. As a consequence, some cases were lost during the study because they failed to attend, or due to a severe disease caused by any of their comorbidities, death or any other social reason.

The collection of data was carried out with a Clinical and Epidemiological Protocol created by the research team for this study and filled out during a personal interview to each patient. In the assessment of HRQOL we used the SF-36 questionnaire, due to its characteristics of viability, reliability, sensitivity to change and transcultural validation in Spain. ${ }^{10,11}$

SF-36 is the most widely used generic questionnaire in the world because it makes it possible to compare the impact/result of an intervention, and it has been used with different chronic diseases and in different population groups. ${ }^{12} \mathrm{SF}-36$ measures HRQOL, it provides a profile of the health condition that can be applied to the general population and to the patients, as well as in studies that assess clinical results. It is also used in musculoskeletal and orthopedic clinical studies to obtain a more detailed description of the Health parameters and to research changes in the health condition. ${ }^{13-15}$

The data collected from the clinical histories and the results of the SF-36 questionnaire were introduced and coded for processing and analysis with the statistical package SPSS version 21 . The statistical analysis included, first of all, a descriptive study (univariate analysis) which calculated the adequate frequency measures to assess the different indexes and indicators, as well as the subsequent descriptive statistics (mean value, standard deviation). Once that the different data were obtained, together with their prevalence and/or proportions we calculated their $95 \%$ confidence interval as a measure of precision (Inferential statistics). Chi-square test was used for the qualitative variables and Student's t-test and ANOVA were used for quantitative variables in order to assess whether the differences observed in the clinical parameters and the components of the SF-36 and other indicators and the abovementioned epidemiological variables regarding the patients were statistically significant or, on the contrary, they could be explained by chance. Finally, a logistic regression model was used so as to assess the influence of the presence or absence of several clinical and epidemiological variables on HRQOL (bivariate and multivariate analysis). The level of statistical significance (error) used by the research team was $5 \%$ (degree of statistical significance $\mathrm{p}<0.05)$.

\section{Results}

The distribution according to sex in our 125 cases was 78 women $(62 \%)$ and 47 men (38\%), with a 1.6:1 man/woman ratio and an average age of 70 years (Figure 1). The most common age was 71 years, with a range between 37 and 86 years (Figure 2). The average time of in-hospital stay was 8.12 days; the most common value was 8 days, and the range was between 4 and 13 days.

Half of our patients had a prior orthoprosthetic history. 33\% had TKA, $13 \%$ had a THA (total hip arthroplasty), and $2.5 \%$ had both prostheses (Figure 3). Also, 20\% of the patients had a prior history of operations in the locomotor system, and $31.2 \%$ of the patients had a history of other prior surgery.

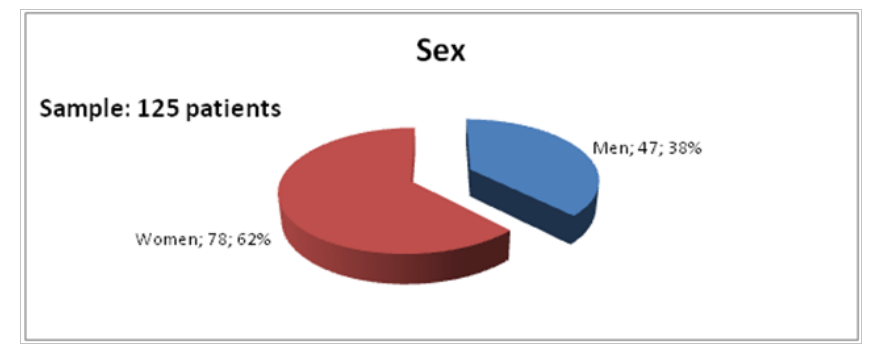

Figure I Sex as a demographic variable in the analyzed sample.

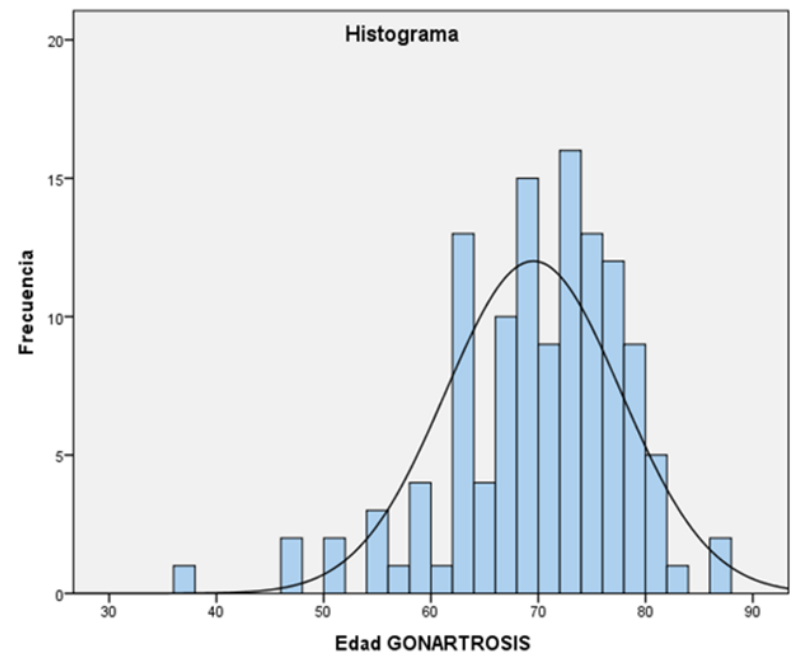

Figure $2 \mathrm{Age}$ as an epidemiological variable, and its distribution on the sample $(n=125)$.

With regard to comorbidity, 95 patients $(76 \%)$ showed associated comorbidity, 28 patients $(22.5 \%)$ presented with a single comorbidity and 67 patients $(53.6 \%)$ revealed two or more comorbidities. Also, in 17 patients $(15 \%)$, the comorbidity was musculoskeletal, and 92 patients $(81 \%)$ showed other comorbidities.

We have observed that osteoarthritis significantly affects all the dimensions of quality of life (before the intervention). All the dimensions of the SF-36 questionnaire reveal a clinical improvement after the operation (TKA) (Figure 4). 


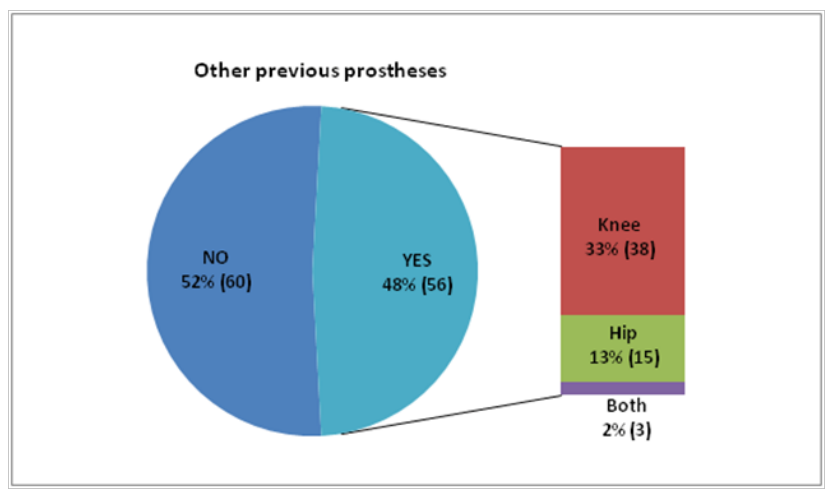

Figure 3 Existence of previous total knee arthroplasty or total hip arthroplasty surgery.

SF-36: DIMENSIONS

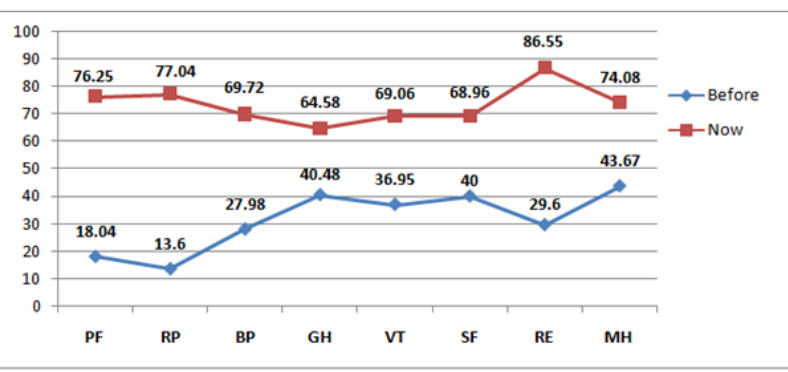

Figure 4 Average values of all the dimensions of the SF-36 survey and improvement before and after 5 the operation (TKA). (PF: physical functioning; RP: Role-Physical; BP: Bodily Pain; GH: General Health;VT:Vitality; SF: Social Functioning; RE: Role-Emotional; MH: Mental Health)

As regards the relation between sex and age and the components of the SF-36 questionnaire, sex has a significant influence $(\mathrm{p}=0.004)$ on the Physical Functioning scale (PF) before the operation. Age also has a statistically significant influence before the intervention on the scales Bodily Pain (BP $p=0.012$ ) and Vitality (VT p=0.002). After the operation (TKA), age also influences the scale of General Health individually ( $\mathrm{GH} \mathrm{p}=0.006)$, and the group of scales of Physical Component (PCS p=0.040) and Mental Component (MCS p=0.002) summary scores, as well as the health transition item SF-2 $(\mathrm{p}=0.009)$ (Table 1). However, despite Age and Sex ask risk factors, TKA improves General and Mental Health Components, on an overall basis (Figure 5).

Table I Association study between components of SF-36 and Sex-Age

\begin{tabular}{lllll}
\hline & \multicolumn{3}{l}{$\begin{array}{l}\text { Sex } \\
\text { DIMENSION }\end{array}$} & \multicolumn{3}{l}{ Age } \\
\cline { 2 - 5 } P value $(\mathbf{p}<0.05)$ & \\
Physical Functioning (PF) & $\mathbf{0 . 0 4 4}$ & 0.958 & 0.120 & 0.682 \\
Role-Physical (RP) & 0.973 & 0.761 & 0.499 & 0.959 \\
Bodily Pain (BP) & 0.147 & 0.133 & $\mathbf{0 . 0 1 2}$ & 0.234 \\
General Health (GH) & 0.357 & 0.182 & 0.457 & $\mathbf{0 . 0 0 6}$ \\
Physical Health COMPONENT & $\mathbf{0 . 3 0 7}$ & $\mathbf{0 . 6 7 9}$ & $\mathbf{0 . 0 9 9}$ & $\mathbf{0 . 0 4 0}$ \\
(PCS) & 0.591 & 0.689 & $\mathbf{0 . 0 0 2}$ & 0.088 \\
Vitality (VT) & 0.774 & 0.747 & 0.402 & 0.667 \\
Social Functioning (SF) & 0.098 & 0.581 & 0.181 & 0.533 \\
Role-Emotional (RE) & 0.264 & 0.634 & 0.073 & 0.448 \\
Mental Health (MH) & & & \\
Mental Health COMPONENT & $\mathbf{0 . 4 3 6}$ & $\mathbf{0 . 2 7 8}$ & $\mathbf{0 . 7 1 6}$ & $\mathbf{0 . 0 0 2}$ \\
(MCS) & 0.638 & 0.269 & 0.527 & $\mathbf{0 . 0 0 9}$ \\
\hline Health Transition Item & & & & \\
\hline
\end{tabular}

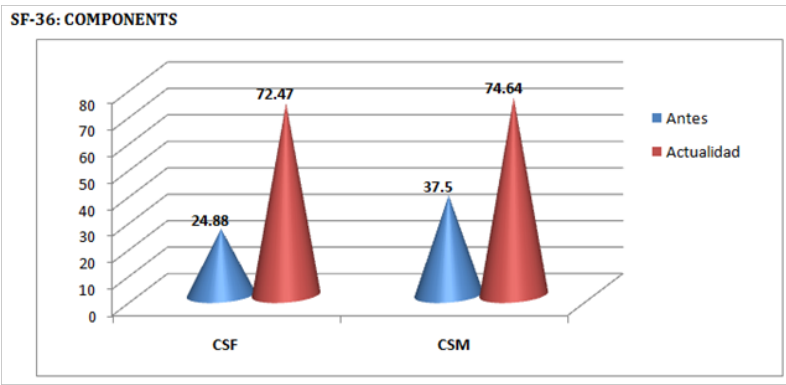

Figure 5 Mean average on Physical Health Component and Mental Health Component before and after the Intervention (TKA) and its improvement.

CSF (Componente de Salud Física): Physical Health Component

CSM (Componente de Salud Mental): Mental Health Component

Antes: Before

Actualidad:After

The association study of HRQOL-SF-36 before and after the operation shows a statistically significant improvement in the scales Bodily Pain (BP $\mathrm{p}=0.000)$, General health $(\mathrm{GH} \mathrm{p}=0.000)$, Vitality (VT $\mathrm{p}=0.005$ ), Social Functioning (SF $\mathrm{p}=0.000$ ), Role-Emotional (RE $\mathrm{p}=0.050)$, and Mental Health $(\mathrm{MH} p=0.000)$. One significant aspect is that the operation (TKA) causes no improvement in Physical Functioning ( $\mathrm{PF} p=0.295)$ and in Role-Physical (RP $\mathrm{p}=0.385$ ) (Table 2). We have also observed that having a prior knee or hip prosthesis improves Physical Functioning ( $\mathrm{PF} p=0.021)$ and Mental Health $(\mathrm{MH}$ $\mathrm{p}=0.036$ ).

Table 2 Association HRQOL-SF36 Before and After

\begin{tabular}{|c|c|c|c|c|c|}
\hline & Before & & After & & $\begin{array}{l}\text { Parametric } \\
\text { Test }\end{array}$ \\
\hline $\begin{array}{l}\text { Items And } \\
\text { Dimensions }\end{array}$ & Average & St. Dev & Average & St. Dev. & $\mathbf{P}$ \\
\hline Sf-3 & 10.40 & 25.63 & 67.74 & 39.91 & 0.004 \\
\hline Sf-4 & 19.20 & 30.96 & 78.63 & 31.34 & 0.385 \\
\hline Sf-5 & 22.00 & 33.23 & 75.20 & 30.95 & 0.285 \\
\hline Sf-6 & 7.60 & 20.13 & 63.64 & 36.51 & 0.217 \\
\hline Sf-7 & 21.77 & 31.39 & 79.84 & 30.52 & 0.219 \\
\hline Sf-8 & 8.74 & 21.82 & 63.71 & 36.81 & $0.24 I$ \\
\hline Sf-9 & 13.20 & 28.50 & 79.03 & 35.55 & 0.500 \\
\hline Sf- 10 & 20.80 & 31.22 & 79.03 & 31.94 & 0.159 \\
\hline Sf-II & 32.40 & 37.70 & 87.50 & 26.76 & 0.098 \\
\hline Sf- 12 & 30.40 & 40.60 & 87.50 & 26.76 & 0.149 \\
\hline $\begin{array}{l}\text { Dimension Physical } \\
\text { Functioning (PF) }\end{array}$ & 18.04 & 22.12 & 76.25 & 24.73 & 0.295 \\
\hline Sf-13 & 16.80 & 37.53 & 79.67 & 40.40 & 0.064 \\
\hline Sf-14 & 12.80 & 33.54 & 75.00 & 43.47 & 0.064 \\
\hline Sf-I5 & 15.20 & 36.04 & 77.42 & 41.98 & 0.211 \\
\hline Sf- 16 & 9.60 & 29.57 & 77.24 & 42.10 & 0.599 \\
\hline $\begin{array}{l}\text { Dimension Role- } \\
\text { Physical (RP) }\end{array}$ & 13.60 & 29.70 & 77.04 & 37.42 & 0.385 \\
\hline Sf-2I & 27.36 & 21.33 & 69.44 & 23.35 & 0.247 \\
\hline Sf-22 & 28.60 & 18.97 & 70.00 & 23.54 & 0.734 \\
\hline $\begin{array}{l}\text { Dimension Bodily } \\
\text { Pain (BP) }\end{array}$ & 27.98 & 17.35 & 69.72 & 20.83 & 0.000 \\
\hline Sf-I & 24.80 & 19.69 & 55.08 & 23.07 & 0.001 \\
\hline Sf-33 & 49.40 & 28.41 & 72.38 & 19.60 & 0.000 \\
\hline Sf-34 & 46.57 & 27.66 & 67.94 & 19.27 & 0.000 \\
\hline Sf-35 & 41.53 & 21.82 & 62.70 & 20.53 & 0.000 \\
\hline Sf-36 & 39.92 & 24.47 & 64.43 & 21.94 & 0.001 \\
\hline
\end{tabular}


Table Continued...

\begin{tabular}{|c|c|c|c|c|c|}
\hline & Before & & After & & $\begin{array}{l}\text { Parametric } \\
\text { Test }\end{array}$ \\
\hline $\begin{array}{l}\text { Items And } \\
\text { Dimensions }\end{array}$ & Average & St. Dev & Average & St. Dev. & $\mathbf{P}$ \\
\hline $\begin{array}{l}\text { Dimension General } \\
\text { Health (GH) }\end{array}$ & 40.48 & 19.05 & 64.58 & 15.28 & 0.000 \\
\hline Sf-23 & 37.76 & 25.68 & 65.60 & 22.66 & 0.345 \\
\hline Sf-27 & 38.21 & 27.22 & 69.35 & 20.94 & 0.000 \\
\hline Sf-29 & 35.45 & 28.03 & 72.26 & 19.20 & 0.000 \\
\hline Sf-3I & 36.29 & 25.16 & 68.55 & 21.66 & 0.099 \\
\hline $\begin{array}{l}\text { Dimension Vitality } \\
\text { (VT) }\end{array}$ & 36.95 & 21.84 & 69.06 & |7.| | & 0.005 \\
\hline Sf-20 & 45.00 & 30.94 & 77.62 & 22.27 & 0.000 \\
\hline Sf-32 & 34.84 & 22.93 & 60.32 & |5.7| & 0.000 \\
\hline $\begin{array}{l}\text { Dimension Social } \\
\text { Functioning (SF) }\end{array}$ & 40.00 & 25.45 & 68.96 & 16.58 & 0.000 \\
\hline Sf-I7 & 28.80 & 45.46 & 87.90 & 32.74 & 0.008 \\
\hline Sf- I8 & 28.00 & 45.01 & 85.48 & 35.36 & 0.005 \\
\hline Sf- 19 & 32.00 & 46.83 & 86.29 & 34.53 & 0.014 \\
\hline $\begin{array}{l}\text { Dimension Role- } \\
\text { Emotional (RE) }\end{array}$ & 29.60 & 43.62 & 86.55 & 32.06 & 0.050 \\
\hline Sf-24 & 45.00 & 31.19 & 76.64 & 17.54 & 0.000 \\
\hline Sf-25 & 46.34 & 32.11 & 79.52 & 16.55 & 0.000 \\
\hline Sf-26 & 38.70 & 25.44 & 68.16 & 22.01 & 0.000 \\
\hline Sf-28 & 47.32 & 30.75 & 76.13 & 17.42 & 0.000 \\
\hline Sf-30 & 41.77 & 28.17 & 70.00 & 21.86 & 0.000 \\
\hline $\begin{array}{l}\text { Dimension Mental } \\
\text { Health }(\mathbf{M H})\end{array}$ & 43.67 & 26.15 & 74.08 & 14.35 & 0.000 \\
\hline $\begin{array}{l}\text { Health Transition } \\
\text { Item Sf-2 }\end{array}$ & 35.04 & 27.01 & 68.13 & 22.67 & 0.041 \\
\hline
\end{tabular}

The multivariate analysis of the determining variable Age vs. the dimensions and components of the SF-36 questionnaire reveals that age has a statistically significant influence before the intervention (TKA) on the scales Vitality (VT $\mathrm{p}=0.013$ ), Social Functioning (SF $\mathrm{p}=0.002)$ and Mental Health (MH $\mathrm{p}=0.017)$. It has a general influence in the Mental Component summary score (MCS $\mathrm{p}=0.019)$. After the operation (TKA), age has an individual influence in the scale of General Health $(\mathrm{GH} p=0.025)$, Social Functioning ( $\mathrm{SF} p=0.021)$ and Role-Emotional $(\mathrm{RE} p=0.004)$, and a general effect on the Mental Component summary score (MCS $\mathrm{p}=0.050$ ). In sum, age has an influence on the Mental Component summary score (MCS) before and after the operation (TKA); and on General Health (GH) after the operation (TKA) (Table 3).

\section{Discussion}

Knee osteoarthritis is one of the diseases with the highest impact regarding the functional disability, and one which greatly affects the personal autonomy of patients. Also, its incidence increases with age, and it affects more than $33 \%$ of people over 70 years in Spain. ${ }^{16}$ The average age in our series at the time of operation is 77 years, and the age distribution shows a normal curve, in accordance with national studies which have shown average ages of $66.5 \pm 6.2$ years. ${ }^{17,18}$ and $74 \pm 2.3$ years. ${ }^{19-21}$ with a progressive ageing in the population. International studies have reported ages of 68 years. ${ }^{21}$ and 72 years. ${ }^{22}$ Consequently, the average age of the patients who were operated and monitored in our series is higher, due to the social and demographic characteristics of the general population of reference, which corresponds to the area of the city and province of Salamanca, part of the Autonomous Community of Castile and León, which has one of the highest indexes of population ageing in Spain.

Table 3 Multivariate Analysis between Age and Dimensions and components of SF-36

\begin{tabular}{|c|c|c|c|c|c|c|}
\hline \multirow{2}{*}{ Depend } & \multicolumn{6}{|l|}{ Independent variable:AGE } \\
\hline & ent Variable: Dimension and Component & Type III sum of squares & DF & Quadratic mean & $\mathbf{F}$ & Sig. $(p<0.05)$ \\
\hline \multirow{11}{*}{ Before } & Physical Functioning-PF & $179 \mid 1.248$ & 30 & 597.042 & 1.349 & 0.148 \\
\hline & Role-Physical-RP & 24020.745 & 30 & 800.691 & .843 & 0.694 \\
\hline & Bodily Pain-BP & 10970.918 & 30 & 365.697 & 1.372 & 0.135 \\
\hline & General Health-GH & 13554.765 & 30 & 451.825 & 1.398 & 0.122 \\
\hline & Physical component-PCS & 10648.756 & 30 & 354.959 & 1.215 & 0.244 \\
\hline & Vitality-VT & 21055.038 & 30 & 701.835 & 1.890 & 0.013 \\
\hline & Social Functioning-SF & 31495.059 & 30 & 1049.835 & 2.267 & 0.002 \\
\hline & Role-Emotional-RE & 69426.059 & 30 & 2314.202 & 1.422 & 0.110 \\
\hline & Mental Health-SM & 29294.345 & 30 & 976.478 & 1.837 & 0.017 \\
\hline & Mental component-MCS & 28946.089 & 30 & 964.870 & 1.820 & 0.019 \\
\hline & Health Transition Item & 22290.452 & 30 & 743.015 & .960 & 0.535 \\
\hline \multirow{11}{*}{ After } & Physical Functioning-PF & 21769.718 & 30 & 725.657 & 1.340 & 0.153 \\
\hline & Role-Physical-RP & 50900.339 & 30 & 1696.678 & 1.416 & 0.113 \\
\hline & Bodily Pain-BP & 13317.352 & 30 & 443.912 & 1.229 & 0.232 \\
\hline & General Health-GH & 9963.148 & 30 & 332.105 & 1.754 & 0.025 \\
\hline & Physical component-PCS & $16 \mid 48.388$ & 30 & 538.280 & 1.452 & 0.097 \\
\hline & Vitality-VT & 8898.696 & 30 & 296.623 & 1.271 & 0.199 \\
\hline & Social Functioning-SF & I I883.479 & 30 & 396.116 & 1.764 & 0.024 \\
\hline & Role-Emotional-RE & 48879.460 & 30 & 1629.315 & 2.125 & 0.004 \\
\hline & Mental Health-SM & 5833.176 & 30 & 194.439 & 1.069 & 0.396 \\
\hline & Mental component-MCS & 9344.806 & 30 & 311.494 & 1.567 & 0.050 \\
\hline & Health Transition Item & $1263 \mid .048$ & 30 & 421.035 & .876 & 0.649 \\
\hline
\end{tabular}

Osteoarthritis usually affects the knee, and its incidence increases exponentially with age, with a clear predominance on women. The observed women/men ratio is $1.6: 1$, in accordance with other national studies, with ratios of $2.7: 1 .{ }^{15} 3: 1 . .^{17,19} 4: 1 .{ }^{16} 4.9: 1 .{ }^{20}$ and with international studies, with ratios of $1.5: 1 .^{22} 1.6: 1 .^{23}$ and $2.2: 1 .^{21}$
Adult and symptomatic patients with osteoarthritis generally have more than one affected weight bearing joint, be it the knee, the hip or a similar contralateral joint. ${ }^{24}$ Some experts also report that $90 \%$ of the patients with knee pain report bilateral symptoms. With regard to the presence of previous joint prostheses, all the studies report 
an orthoprosthetic history. In our series, $33 \%$ of the patients had a previous prosthesis in the knee, $13 \%$ in the hips and $2 \%$ in both. National studies have revealed contralateral surgery in $24.6 \%$ of the patients $<75$ years old and $33 \%$ in patients $>75$ years old. ${ }^{20}$ and other international studies have found contralateral surgery of the knee in $17 \%{ }^{25}$ of the patients; in $20 \%$ of the patients $<80$ years old and in $54 \%$ of the patients $>80$ years old, and $35 \%$ of the patients showed THA. ${ }^{26}$ These results prove that osteoarthritis is a bilateral condition that particularly affects weight bearing joints. All the studies reveal orthoprosthetic records similar to those of our series, and these records are higher in older groups. The results observed in patients with previous prosthesis of the knee or the hips are associated with a faster and steadier improvement of Physical Functioning and Mental Health, and this improvement may be due to the better mental predisposition of the patients caused by the previous surgical experiences and by the process of adaptation to living with prosthesis.

The average in-hospital stay in our study is 8.2 days, with a range between 4 and 17 days. All the studies that have been carried out, both national. ${ }^{16,20}$ and international. ${ }^{27,28}$ show similar periods of average inhospital stay, and they all report a decreasing evolution of this factor. This decrease has been made possible thanks to the improvements in the surgical techniques and the program for immediate postoperative rehabilitation treatment which has been implemented in the medicalsurgical protocols in order to improve the quality of the care process, its effectiveness and efficiency.

Regarding HRQOL, we have observed a clinical improvement in all the dimensions of the SF-36, and this improvement is significant in all sections except for Role-Physical and Physical Functioning. This result may seem in conflict with what was reported by other experts on TKA, who state that it substantially improves Physical Functioning, as published by some researchers. ${ }^{21}$ and it is only observed in patients with a previous prosthesis. Nevertheless, it may be due to the conditioning of age and comorbidity, which are variables that affect the immediate postoperative period in which the HRQOL questionnaires were filled out. This means that patients need more time to notice a significant clinical improvement with regard to Physical Functioning (PF). Some authors state that a previous joint prosthesis does not lead to worse results after the operation, as was observed in our series. ${ }^{20}$ Other researchers have observed that preoperative factors are predictors for mobility and results. ${ }^{27,29,30}$

For its part, age has an influence on Bodily Pain (BP) and Vitality (VT) before the intervention, and it leads to worse tolerance and causes higher functioning disability and dependence in these patients. Of course, and according to what has been published, the main predictor for comorbidity, postoperative complications and mortality is age .$^{16,30}$ That is, the age of patients is associated to comorbidity and/or chronic multiple pathologies, which leads to lower autonomy, higher disability and physical, emotional and social dependence associated to ageing. Patients $>60$ years with osteoarthritis, such as those in our series, present with more limitations in Activities of Daily Life than patients of the same age without osteoarthritis. ${ }^{31}$ In line with what was observed in our series, most of the studies..$^{14,16,21,22,24,26}$ report that total replacement arthroplasty improves pain, Physical Functioning, Mental Health, Social Activity and HRQOL. Knee osteoarthritis produces limitations in ADLs and therefore limits social functioning, and although after the operation there is an improvement in all other dimensions, and particularly pain and physical functioning, it is difficult for older patients to recover the lost social functioning due to their advanced age and the fact that they have comorbidities, as has already been shown by other studies. ${ }^{32}$
On the other hand, when the results from the different components of HRQOL in SF-36 in our series are compared with the general population in Spain. ${ }^{11}$ which is our standard population of reference, only Social Functioning is lower, while five of them show similar levels and two of them, Role-Emotional and Mental Health, show an improvement. Consequently, we can state that the operation of total knee arthroplasty is justified according to the perception of clinical improvement and the improvement of HRQOL reported by the patients.

\section{Conclusion}

According to what was observed in this study, we can state that TKA significantly improves HRQOL in all its dimensions and components, except for Physical Functioning and Physical-Role; although they also improve over time after the intervention. Sex affects Physical Function in Knee OA. Age has an impact on Bodily Pain and Vitality on knee OA. Age influences on General Health and Physical and Mental Components after TKA.

\section{Conflicts of interest}

Each author certifies that he or she has no commercial associations that might pose a conflict of interest in connection with the submitted article. No benefits in any form have been received or will be received from a commercial party related directly or indirectly to the subject of this article.

\section{Authors' contributions}

ME Fernández-Cuadros participated in acquisition of patients' data, drafting and designed of the article and analysis and interpretation of results. OS Pérez-Moro, participated in acquisition of patients' data. Montserrat Alonso-Sardón and Helena Iglesias-de-Sena supervised, analysed and interpreted the results. JA Mirón-Canelo participated in the conception and design of the study, designed the manuscript, supervised and interpretation of results. All authors read and approved the final version of the manuscript.

\section{Acknowledgements}

In memory of Dr. José Antonio de Pedro-Moro, Surgeon and Professor of Salamanca's University Hospital, responsible for the study design and the surgical treatment of the sample that constituted this quasi-experimental study. Without his help this clinical research could not be accomplished.

\section{References}

1. Roig Escofet D Artrosis de las articulaciones periféricas. Editorial Momento Medico Ibero Americana. Madrid, Spain. 2002

2. Quintero M, Monfort J, Mitrovic D Osteoartrosis: Biología, fisiopatología, clínica y tratamiento. Editorial Médica Panamericana. Madrid, España, Spain. 2010

3. Casals Sánchez JL Guías Clínicas, Artrosis. Ediciones Semergen, Madrid, Spain. 2011

4. Moskowitz RW The bourden of osteoarthritis: clinical and quality of life issues. Am J Manag Care. 2009;15:223-229.

5. Monfort J Artrosis. Fisiopatología, diagnóstico y tratamiento. SER (Sociedad Española de Reumatología. Editorial Médica Panamericana. Madrid, España, Spain. 2010

6. Alonso M, Mirón JA Sistema de Información Sanitaria. Indicadores de Salud, Bienestar y Calidad de Vida. En: Guía para la elaboración de Trabajos Científicos. Grado, Máster y Posgrado, Salamanca, Gráficas Lope, p. 2013;55-66. 
7. Rodríguez Merchán EC Cirugía Ortopédica y Traumatología de la Rodilla. Estado actual. Editorial Médica Panamericana. Madrid. España, Spain. 2011

8. US Preventive Task Force Guide to Clínical Preventive services: an assessment to the effectiveness of 169 interventions. Wiliams and Wilkins, Baltimore, USA. 1989

9. Centre for Evidencice - based Medicine (CEBM): Levels of Evidence (March 2009). CEBM, Oxford University, USA. 2013

10. Villagut G, Ferrer M, Rajmil L et al. El cuestionario de Salud SF 36 español: una década de experiencia y nuevos desarrollos. Gac Sanit. 2005;19(2):135-150.

11. López-García E, Banegas JR, Graciani Pérez-Regadera A et al. Valores poblacionales de referencia de la versión española del cuestionario SF 36 en población adulta de más de 60 años. Med Clin (Barc). 2003;120(15):568-573.

12. Mirón Canelo JA, Alonso Sardón M, Serrano López de las Hazas A De Godos N, Sáenz González MC Health Related Quality of Life (HRQL) in people with intellectual disability. Pan Am J Public Health. 2003;24(5):336-344.

13. Soderman P, Malchan H Validity and reliability of Swedish WOMAC osteoarthritis index. A self-administered disease-specific questionnaire (WOMAC) vs generic instruments (SF-36 and NHP). Acta Orthop Scand. 2000;31(1):39-46.

14. Ostendorf M, Van Stel HF, Buskens E et al. Patient reported outcome in total hip arthroplasty. A comparison of five instruments of health status. J Bone Joint Surg. 86(6):801-808.

15. Quintana JM, Escobar A, Aróstegui J et al. Health related quality of life and appropriatness of knee or hip joint replacement. Arch Intern Med. 2006;166(2):220-226

16. Moreno Palacios JA, Catedra Valles E, Plazas Andreu N, Sancho Loras R, Manjón-Cabezas Subirats J, et al. Comparación de los resultados en función de la edad de pacientes ancianos con artroplastia total de reemplazo. Rev Esp Geriatr Gerontol. 2009;44(3):120-123.

17. Pagés E, Iborra J, Rodríguez S et al. Prótesis total de rodilla. Evolución del tratamiento rehabilitador intrahospitalario durante el decenio 1988-1998. Rehabilitación (Madr). 2000;34(5):347-353

18. Pagés E, Iborra J, Jou $\mathrm{N}$ et al. Prótesis total de rodilla. Valoración functional y satisfacción personal del paciente a los 5 años. Rehabilitación (Madr). 2001;34(1):3-8.

19. Pagés E, Iborra J, Rodríguez S et al. Prótesis total de rodilla. Estudio de factores determinantes del alta hospitalaria en Rehabilitación. Rehabilitación (Madr). 2002;36(4):202-207.
20. Ramón Rona S Función y calidad de vida de los pacientes con gonartrosis antes y después de la artroplastia de sustitución. Coste de la gonartrosis según la esperanza de vida y de la cirugía. Tesis para optar al Grado de Doctor en Medicina y Cirugía. Barcelona, p. 2001;1-86.

21. O'Brien S An outcome study on average length of stay following total hip and knee replacement. J Orthop Nursing. 6:161-669.

22. Bachmeier CJM, March LM, CrossMJ et al. A comparison of outcomes in osteoarthritis patients undergoing total hip and knee replacement surgery. Osteoarthr cartilage. 2001;9(2):137-146.

23. Wallace DA, Car AJ, Murray DW et al. Etiological factors in severe osteoarthritis of the knee. The knee. 1995;2(2):113-115.

24. Dawson J, Linsell L, Zondervank K et al. Epidemiology of hip and knee pain and its impact on overall health status in older adults. Rheumatology. 2004;43(4):497-504.

25. Jones A, Voaklander D, Johnston W et al. The effect of age on pain, function and quality of life after Total Hip and Knee Arthroplasty. Arch Intern Med. 2001;161(3):454-460.

26. Mangione C, Goldman L, Orav J et al. Health Related quality o flife after elective surgery. Measurement of longitudinal changes. J Gen Intern Med. 1997;12(11):686-697.

27. Ackerman J, Graves S, Bennell K et al. Evaluating quality of life in hip and knee replacement: Psicometric properties of the World Health Organization Quality of Life Short Version Instrument. Arthritis and Rheumatism. 2006;55(4):583-590.

28. Nilsdotter AK, Lohmander LS Age and waiting time as predictors of outcome after total hip arthroplasty for osteoarthritis. Rheumatology. 2002;41(11):1261-1267.

29. Parent E, Moffet H Pre-operative predictors of locomotor ability two months after Total Knee Arthroplasty for severe osteoarthritis. Arthritis and Rheumatism. 2003;49(1):36-50.

30. Katz JN Total joint replacement in osteoarthritis. Best Pract Res Clin Rheumatol. 2006;20(1):145-153.

31. Singh J, Sloan J Health related Quality of life in veterans with prevalent Total Knee Arthroplasty and Total Hip Arthroplasty. Rheumatology. 2008;47(12):1826-1831.

32. Bjorgul K, Novicoff W, Saleh K Evaluating comorbidities in total hip and knee arthroplasty: available instruments. J Orthopaed Traumatol. 2010;11(4):203-209. 